Laurence J. O'Toole، Jr.

The University of Georgia

University of Twente, The Netherlands

\title{
Networks and Networking: The Public Administrative Agendas
}

Editor's Note: We are publishing a series of essays in 2015 to commemorate influential contributions to public administration that appeared in Public Administration Review since its inception in 1940. In this essay, Laurence J. O’Toole, Jr., revisits his groundbreaking 1997 article, "Treating Networks Seriously: Practical and ResearchBased Agendas in Public Administration." O’Toole assesses the impacts of the original article and offers an agenda for network research that builds upon what we have learned since 1997.

\begin{abstract}
Published in 1997, the article "Treating Networks Seriously: Practical and Research-Based Agendas in Public Administration" outlined the importance of networks for the field of public administration and suggested a series of research agendas that should be pursued. That argument has received substantial attention in the years since. Research on networks and networking has made substantial progress, particularly on some questions-the descriptive agenda, for instance, and some aspects of the practical agenda. However, considerable work remains to be done. More needs to be known about the ways in which networks and networking behavior can shape performance and affect the most salient values in our governance systems; better empirical theory is also needed in this regard. Such further developments would be of immense value to the practice of public administration. The world of public administration has for some time been treating networks seriously, but the work is far from complete.
\end{abstract}

$\mathrm{W}$ hen I wrote "Treating Networks Seriously: Practical and Research-Based Agendas in Public Administration" (O’Toole 1997b), I was convinced of the emerging importance of the topic and intended to bring the multiple strands of extant research and several emerging research agendas together into one succinct argument. I did not expect, however, that the contents would resonate among so many. The article is currently one of the 10 most-cited articles in the 75-year history of Public Administration Review. ${ }^{1}$ Some of the attention that the article has received is surely attributable to its timing: it was published just as a great deal of network-themed research was beginning to appear. But I also think that the article drew-and draws-interest because it sketched the importance of the theme and the value of several related clusters of research questions in a fashion that presented a large research agenda that could be of considerable value to the field. That value derives partially from the importance of the research agendas themselves, as well as from the implications of this work for the practice of public administration.

In this new article, I remind readers of the earlier argument and the several related research agendas called for in the original article. I then sketch progress since 1997. The present article also indicates some of the ways that today's public administrators may be assisted by the advances made by researchers in treating networks seriously.

\section{Clarifying and Delimiting the Topic}

Networks are structures of interdependence involving multiple organizations or parts thereof, where one unit is not merely the formal subordinate of the others in some larger hierarchical arrangement (O'Toole 1997b, 45). ${ }^{2}$ Further, externally oriented "networking" efforts on the part of public managers can perform a number of functions, such as building support, negotiating with others in an agency's external environment, contributing to the management of multiorganizational efforts, exploiting opportunities, protecting the core organization from challenges or threats, and sometimes helping move a set of organizations toward an objective. ${ }^{3}$

Networks typically do not replace bureaucratic organization; instead, they add one or more layers of structural complexity, as public agencies are interwoven with counterparts from the same government, or other governments of the same sort-as with multiple governments in metropolitan regions (Feiock and

\section{5th Anniversary Article}

Laurence J. O'Toole, Jr., is the Margaret Hughes and Robert T. Golembiewski Professor of Public Administration as well as Distinguished Research Professor in the Department of Public Administration and Policy, School of Public and International Affairs, The University of Georgia. He is also professor of comparative sustainability policy studies in the Department of Governance and Technology for Sustainability at the University of Twente, The Netherlands.

E-mail: cmsotool@uga.edu
Public Administration Review. Vol. 75, Iss. 3, pp. 361-371. (C) 2014 by The American Society for Public Administration. DOI: 10.1111/puar.12281. 
Scholz 2010; Frederickson 1999)—or from other levels of governments, or even from ministries and agencies that are a part of national regimes in other countries (Nicolaidis and Howse 2001). They may also be linked through contracts or other ties with forprofit or nonprofit organizations-or even all of the above.

So individuals as actors can be seen simultaneously as occupants of positions within a public administrative organization and as components of one or more multiorganizational web(s) of action built in one way or another around functions or public problems. As scholars of policy implementation have long noted, these overlapping albeit different roles convey somewhat differing logics, incentives, and priorities (Hjern and Porter 1981), a point that can complicate all arrangements.

Elsewhere (e.g., O’Toole 2010), I have tried to clarify some basic points about the "networks" theme. Some of these can be mentioned briefly before I assess what progress has been made since the appearance of the original article. Still, this article necessarily offers limited coverage of a range of network-related research. Very little is included from the growing work employing social network analysis (but see Hennig et al. 2012) or on policy networks, despite the fact that in corporatist settings, there may be substantial overlap between policy and management arrays. Likewise, the present treatment leaves aside much of the methodological and substantive developments in the network literatures of such fields as physics, computer science, and international relations. (For some coverage of certain broader aspects, see Berry et al. 2004; Isett et al. 2011; Lecy, Mergel, and Schmitz 2014.)

First, network forms of whatever sort are not necessarily voluntary-that is, self-organizing — nor even necessarily cooperative. A role of governments has certainly been to force, or at least press toward, networked forms of administrative action-sometimes with direct hierarchical control or regulation as a default (Scharpf 1993), upon failure of cooperative effort. The vast majority of possible networked ties involve mixed motives, with those involved neither in full agreement with nor in strident opposition to each other but somewhere in between. The combination of complex patterns that are partially mandated and partially self-organized, with varying combinations of integrative ties, suggests an interestingly complicated terrain, one that cannot easily be comprehended with many of the approaches often used.

Second, it is quite important to encourage research from a network perspective, but saying so does not imply that this is the only research agenda worth pursuing, nor does it necessarily entail any endorsement of network forms or any carte blanche for whatever happens in and through them. Networks and networking can encourage and produce beneficent outcomes — and definitely worrisome ones, as discussed later in this article.

Third, the relevance of networks and managerial efforts associated with the interdependent environment of public organizations does not mean that the traditional attention to internal management is misplaced. In fact, management within such organizations remains important, and a number of careful studies have shown that traditional internal functions of management - such as managing the organization's human resources and budget—can be shown to contribute in important ways to organizational performance (examples include Andersen and Mortensen 2010; Donahue et al. 2004; Meier and O’Toole 2009; O’Toole and Meier 2009; Roch, Pitts, and Navarro 2010). Managing organizations matters-and so do networks and external managerial effort in the networked environment (O’Toole and Meier 2011).

\section{The Multiple Network Agendas}

In the remainder of this article, I revisit the several agendas thatas I argued in the original article-should receive attention from those who choose to treat networks seriously. I rearrange the order of those agendas so that the current article culminates in a consideration of some of the practical issues entailed or addressed by the research work that has developed since the original argument was framed. The review in this article is based largely on my own reading of the significant developments in the literature rather than a formal or bibliometric analysis (for a recent example of a formal citationbased study, see Lecy, Mergel, and Schmitz 2014).

\section{The Conceptual and Descriptive Agenda}

The earlier article called for more conceptual clarity in the treatment of networks. It also noted that basic research on important descriptive aspects of networks was sorely needed. "At least three kinds of efforts are warranted: (1) determining what networks, and what kinds of networks, can be found in today's administrative settings; (2) examining the historical dimension of network formation and development; and (3) exploring the array of networks in a broadly comparative perspective" (O’Toole 1997b, 48). On these sorts of issues, considerable progress can be noted. ${ }^{4}$

On the conceptual front, the good news is that many differentiated aspects of networks have been sketched and clarified. In work that began prior to the publication of my article (see Berry et al. 2004 for a discussion), social network analysis, in particular, has catalyzed the identification of many features of networks. We can define and measure many aspects of network structures and also, when data are available, their changes over time. Computer software programs are now widely available and frequently used to analyze networks and network characteristics. In addition, simulations conducted through agent-based modeling probe the dynamics of large, complex networks. This progress now allows social scientists and others to be precise about network characteristics and how they might change over time. There are certainly practical applications to this work as well, most obviously in such fields as law enforcement and counterterrorism. (Indeed, some early studies of so-called dark networks have sought to elucidate networks such as organized crime, smuggling, and terrorist arrays; see Breiger et al. 2014; Milward, Kenis, and Raab 2006; Raab and Milward 2003.) While some of this work carries potentially important theoretical implications (e.g., the work on "structural holes" by Burt 1995), the less happy news is that we now have many defined features of networks without much clarity and consensus as to which are most important to understanding how networks operate and without sufficient theoretical development—especially in public administration — to guide our attention to particular features of networks.

With regard to the descriptive agenda, we now have much data at hand. We are beginning to have substantially more systematic information about the presence and shape of networks as they 
pertain to public administration, as well as their involvement in policy making and other processes. We have information on public program and public sector-focused network forms in U.S. local, state, and national governance, plus British, Dutch, Swedish, Finnish, and Thai administrative settings, among others (Agranoff and McGuire 2003; Huxham, Vangen, and Eden 2000; Jacobson, Palus, and Bowling 2010; Jokisaari and Vuori 2010; Koppenjan and Klijn 2004; Krueathep, Riccucci, and Suwanmala 2010; Lundin 2007; Moynihan 2009). We now have detailed analyses of especially important public administrative networked settings, such as New Orleans during and after Hurricane Katrina (Kiefer and Montjoy 2006; Koliba, Mills, and Zia 2011; Moynihan 2012). Indeed, considerable evidence has been developed that networks and networking are no less evident across Europe than in the United States (Robinson 2006; see also Kickert, Klijn, and Koppenjan 1997; Koppenjan and Klijn 2004; Torenvlied 2012).

Further, we now know that networks operate not only within national settings but also across them-among professionals and policy specialists who exchange information and pass along technical and policy innovations to the often far-flung others (see Kim, Ashley, and Lambright 2015; Koppell 2010). And the emergence of transnational, functionally specific regimes for managing policy issues that span national borders has been an important development that is well recognized among specialists in international relations but has gone unnoticed among most students of public administration (for an exception, see O’Toole and Hanf 2002).

As for systematic descriptive information, the research literature now shows at least some progress. In particular, work by Hall and O'Toole $(2000,2004)$ reports details regarding a particular subset of networked arrangements: U.S. national programs authorized by statute and often further developed through regulations. The results of these investigations cover only a limited and somewhat distinctive slice of the world of networks, and they also use rather conservative estimates of the prevalence of networked interdependence on behalf of policy action. Even so, the findings are clear: huge majorities of new or substantially revised U.S. federal programs require or strongly encourage action that spans two or more organizations. What is more, statutorily stipulated patterns are typically rendered even more complex-more organizational actors, more complex forms of interdependence-during the process, resulting in detailed regulation.

The 1997 article also identified the need to consider networks in "historical perspective." A simple way of putting the question is, are networks relatively new, or recently important, in public administration? Or have they been empirically significant for some time? If the latter, does the upsurge in interest in networks signal merely the shifting attentions of researchers?

It is clear that the attention now directed toward networks and interorganizational collaborative public action is not merely a faddish idea in the world of research. For instance, policy makers and public management practitioners have recently paid substantial attention to the subject and sought to work such themes into the conduct of policy and management action. The Government Performance and Results Modernization Act of 2010 was explicitly designed to incorporate cross-agency collaboration and coordinated action into the policy agenda of the federal government, with a stipulation that metrics for certain varieties of networked public action should be a regular part of assessing the performance of public agencies and programs. Similarly, the European Union has emphasized a theme of governance, extending beyond governments (Lafferty 2004), as it has encouraged successful adaptation to the demands of such policy challenges as sustainable development. And there is no denying the great interest among all sorts of stakeholders recently in collaboratives, public-private partnerships, and the importance of nonprofits working with governments to deliver public services.

At the same time, it would be a distortion to suggest that the recent attention directed by both researchers and practitioners toward networked arrangements signals something altogether new in public administration. The historically grounded scholarship of Daniel Elazar (1962) sketches a long history of federal-state cooperation in numerous areas of policy, and these efforts often included interorganizational ties. The contributions of Elinor Ostrom (1990) include extensive meta-analysis of long-standing multiactor selfgoverning common-pool resource systems extending back hundreds of years, in some cases, and ranging from irrigation systems in Nepal to forests in South America to fisheries in the North Atlantic. The research literature on policy implementation for more than 30 years has included an emphasis, particularly among European specialists, on "implementation structures" as a "new [that is, underrecognized] unit of administrative analysis" (Hjern and Porter 1981). Much of this work has consisted of case studies or small numbers of cases for intensive analysis, but some has documented larger numbers of interorganizational arrangements involved in executing public programs (e.g., O’Toole and Montjoy 1984).

Further, Hall and O'Toole's work (2000) shows that the interorganizational nature of new or substantially revised federal programs did not increase between two similarly active Congresses convened 28 years apart (1965-66 and 1993-94). While the network theme has thus been especially prominent in recent years in both research and governments' attention, networks and public administration are not an empirically new phenomenon (for a different view and a longer historical overview, see Raab and Kenis 2009).

And how much do we know about networks in a "broadly comparative fashion"? Here, there has been both progress and also practical difficulty in assessing definitive answers. One challenge is that actually mapping out the details of network arrays is typically very labor intensive, and thus many such comparative studies encompass only a few networks for consideration (e.g., Milward et al. 2010; Provan and Milward 1995). Given the documentation of networked arrays in so many locales, as indicated earlier, we certainly can say that these patterns generally are not specific to one policy sector, national setting, or even level of socioeconomic development. But it will take time to carefully compare network structural features across very different fields and locations.

A bit more can be said of a comparative nature about the networking behaviors of the top managers of public programs. Earlier, this article distinguished managerial networking from the structural networks in which many programs are executed. Both may be significant, but these are not identical features. It is possible to 
conduct analyses of large numbers of public managers to ascertain the extent of their networking activities; this sort of study is equivalent to examining the "ego networks" of such managers and can be undertaken through survey methods, in particular (Meier and O'Toole 2005). It is clear from accumulated studies that networking is a regular part of public managers' activities, whether in Texas school districts (Meier and O'Toole 2001, 2003) or in English local authorities (Walker, O'Toole, and Meier 2007), whether in Danish (O'Toole and Pedersen 2011) or Dutch (Torenvlied et al. 2013) educational systems, whether in U.S. law enforcement systems (Nicholson-Crotty and O'Toole 2004) or in state budget and finance offices (Donahue et al. 2004). Managers' efforts to assist in encouraging collaboration for economic development at the local and regional levels in the United States also encompass considerable networking efforts of various sorts (Agranoff and McGuire 2003). The details of the patterns vary by setting and policy sector, as one would expect, but networking by managers is now a welldocumented phenomenon, and some careful comparisons are now available in the research literature.

All in all, therefore, substantial progress has been achieved regarding the descriptive agenda, even if it is important to know much more.

\section{The Agenda of Empirical Theory}

Knowing about the presence of networks and networking in so many governing systems is helpful but only takes one so far. Why do these patterns emerge? And what differences do they make? This latter question is particularly important, as practicing administrators may need to know how to operate effectively in network settings.

\section{Networks as dependent variable. Why}

networked public action? Why is so much public management situated in settings in which multiple actors and organizations are linked, often in complicated ways? Answering

this question requires a complex and related set of responses. An abbreviated explanation can be offered here. In pluralistic systems in which there may be good political reasons to add actors to implementation arrangements to reduce threats or increase support for programs during execution, networks may develop as part of what one might call co-optative strategies (Pressman and Wildavsky 1984; Selznick 1949) or as part of an effort to distance state-centric institutions from contentious policy issues (see O'Toole and Meier 2004a).

Ideological or at least political preferences for private sector involvement in delivering results add links and structural complexity to what could otherwise be accomplished through direct provision. And there may be technical, or capacity-building, stimuli: adding other actors, as nodes in a network, can include needed expertise or experience and additional leverage for addressing a public challenge, even if such networked arrays are more challenging to manage toward effective collective action (O’Toole, Hanf, and Hupe 1997). We can assume, therefore, that networks can be expected to be part of the institutional landscape for public administration for the foreseeable future.

There has been some systematic study of the determinants of networks and networking in the public sector. This subject is intriguing, in part because the development of interorganizational links seems different in the public and nonprofit sectors than in the case of for-profit organizations (Isett and Provan 2005). The factors influencing network characteristics are likely to vary, furthermore, by network type and policy problem or sector. A study of network formation in Thailand found that the variables most important in explaining the emergence of networks there were the nature of the program and the presence of management capacity, with political climate also relevant (Krueathep, Riccucci, and Suwanmala 2010). Graddy and Chen (2006) found that the features that helped explain network size and scope for the delivery of social services in the Los Angeles area were the availability of potential partners, the scope of the required services, and the ethnic homogeneity of the service recipients. Another study found that the tangibility of resources (funds being more tangible than information, for example) affects the characteristics exhibited by networks as they are formed (Provan and Huang 2012). With regard to managerial networking behavior, some work indicates that there are both internalorganizational and also external-environmental variables that help explain the extent of networking that public managers engage in (Andrews et al. 2011). That study found that "loose" organizational structures and diverse stakeholder demands are positively associated with the extent of managerial networking, but defensive and reactive strategies, along with unpredictable stakeholder demands, are negatively associated. And a recent, carefully conducted study has explored the determinants of changes in the networking behavior of public managers (Rho 2013).

Networks as independent variable. Networks can be influential in shaping the processes, outputs, and outcomes of public action. Indeed, a considerable quantity of research has been devoted to this issue in the years since my original article appeared. While the full range of studies on this subject cannot be analyzed in the scope of this one article, some sense of the progress being made can be

offered (see Turrini et al. 2010 for an expanded review). The general bottom line here can be succinctly offered: networks and networking matter; we now know much more than we did two decades ago about how networks shape results, but there is much more to be learned.

Some work on this question has been developed through the systematic examination of a small number of cases. Provan and Milward (1995, 2001) are among those who have used this approach and among the few to try to assess the overall effectiveness of networked public action (see also Akkerman, Torenvlied, and Schalk 2011). Their findings with regard to networks for the seriously mentally ill point toward network integration, external control, system stability, and the munificence of the external environment as influences on network effectiveness (Provan and Milward 1995).

A considerable quantity of significant research has focused on the issue of how networks in which collaborative behavior is required or encouraged tend to perform. Some of this work predated the 1997 article, of course. For instance, studies of policy implementationparticularly from the so-called bottom-up perspective-have touted and, to some extent, demonstrated the advantages of problemsolving, collaboratively oriented networked action. Such advantages can accrue in particular when policy problems must rely on 
coproduction for effective resolution, when precise outputs cannot be stipulated ex ante, and when dynamic conditions preclude effective programming from the top, or center, of governmental action (Elmore 1985; Hjern and Hull 1982; Matland 1985). Other work on collaboration in networks draws less from the research tradition in policy implementation and more from public administration, conflict resolution, and community problem solving (Agranoff 2012; Agranoff and McGuire 2003; O'Leary and Bingham 2009).5

As noted earlier, networking — particularly by managers- has been analyzed for its effects on public program performance. This work typically moves the unit of analysis from the organization (and/or network) to the individual. Influences from both can be important. Analysts have investigated the ego networks of public managers and their possible effects on organizational results. Surveys, for instance, have been used to ask managers with whom they interact externally and how frequently. Their responses provide data that can be analyzed for performance-related effects. We now know that managerial networking can improve outcomes (Meier and O'Toole 2001, 2003), not simply in a linear, additive fashion but also in a nonlinear way with respect to selected resources. Networking by others can also help (Nicholson-Crotty and O'Toole 2004). Still, not all stakeholders necessarily benefit, as explained later. Managerial networking generates diminishing returns, although when managerial quality is taken into account, that result disappears-at least in part because talented managers are more selective in using their time wisely (Hicklin, O'Toole, and Meier 2008). The performancerelated effects of such networking are boosted in the presence of enhanced managerial capacity, at least in situations in which managers' organizations confront jolts or negative shocks from the networked setting (Andrews et al. 2010; Meier and O’Toole 2009). Finally, the performance-enhancing aspects of managerial networking are likely dependent on the context, including the political context: in more consensual political systems, such as corporatist governance systems, we would expect the networking activities of managers to be less important in shaping results (O'Toole and Meier 2014). Empirical studies find managerial networking to be substantively quite significant in the United States, less so in English local government (Andrews et al. 2010), and much less so in Danish public education (Meier et al., forthcoming).

Some researchers are implicitly critical of such studies. Milward, Provan, and colleagues (e.g., Milward et al. 2010) have chosen to concentrate on intensive examination of small numbers of cases, as such work allows for determining detailed network characteristics; most of the managerial networking studies forgo that detail in favor of examining large numbers of cases and incorporating statistical controls into the analysis (for a methodological treatment of some of these issues, see Meier and O'Toole 2005). Others find some of this research to be metaphorical, despite its attention to measurement and statistical inference (Isett et al. 2011). Still, much more large- $N$ investigation of managerial networking needs to take place, and in settings of widely varying features.

Most of the research conducted on managerial networking and performance leaves aside the structural networks themselves in favor of examining networking behavior, but there are exceptions. O'Toole and Meier (2004b) have been able to show that structural networks (measured through patterns of interdependence built around intergovernmental aid) shape performance, and managerial networking (managers' reported interaction patterns) does as well. The two sets of features interact in complicated ways in terms of their performance effects. For instance, managerial networking matters more to performance when core organizations operate in networks in which they are more financially dependent on others.

Another very important and distinctive line of research is the scholarship of Elinor Ostrom and colleagues from the Institutional Analysis and Development (IAD) school. Although it is not focused on networks per se but rather on multiactor situations-especially situations requiring the management of common pool resourcesthe theoretical and empirical work conducted through IAD has explicated "institutional diversity" (Ostrom 2005) and how multiple actors can function together to solve collective action problems, sustain resources, and achieve high levels of performance. These results are clearly not inevitable, and the real strength of Ostrom's work has been to specify many of the variables that can explain the range in outcomes across very different settings. This research is rich and persuasive, in part because of the wide array of research methods and designs mobilized to analyze such situations (Poteete, Janssen, and Ostrom 2010). While Ostrom typically has eschewed reliance on the theories and literature of public administration, and while she often has expressed a normative preference for self-organizing systems over government-organized ones, her work represents an important contribution to public administration broadly construed and, in particular, to the effort to treat networks seriously.

While much of the foregoing work highlights the positive contributions of networks and networking to performance, it would be misleading to imply that networks and networking behavior by managers unambiguously produce happy and beneficent outcomes. Most of the time, when networks and networking are treated as independent (or moderating) variables, the story line has been positive (see O’Toole and Meier 2004a; Torenvlied 2012). Particularly when the focus is on collaborations, the subtext has been that partnerships and coproduction among different and even disparate actors leverages more for the public good. While there is much good sense in this literature-stakeholders in communities working together can indeed improve prospects for policy success, environmental regulators engaged in negotiation with regulatory targets rather than in top-down unilateral directives can sometimes produce Pareto improvements, and nonprofit organizations can help generate substantially greater returns for given levels of public funds expended — there are also grounds for caution.

First of all, although networks and networking have been found to contribute to public sector performance, this finding is not always supported. Torenvlied (2012) documents instances in which networked action causes disruption and increases conflict. Second, managerial networking can boost performance, but that may not be the case for all performance measures (O'Toole and Meier 2004a). Because virtually all public organizations are tasked with multiple goals, it may be important to determine how robust the findings are regarding the relationship between networking behavior and performance. Third, networks and networking expose public managers and their organizations to pressure from stakeholders. This can indicate distributional consequences to managerial networking: to the extent that managers are exposed to contact with those outside 
the organization, there can be increased responsiveness to the more powerful elements in the environment-and correspondingly less to those representing the more marginalized elements (see O'Toole and Meier 2004a). And fourth, close collaboration among actors in networks can induce not only performance but also a host of less attractive effects, including corruption and other forms of insider dealing. And there is also the phenomenon of "dark networks," mentioned earlier.

In short, networks and networking may or may not be worth encouraging. The devil here, as so often, lies in the details.

\section{The Normative Agenda}

How do networks and networking relate to the normative setting in which public administrators operate? In the earlier article, I sketched the need for scholarship focused on normative issues raised by the subject of networks (O’Toole 1997b, 50). During the intervening time, an encouraging development has been the several strands of normative analyses regarding certain aspects of networks and networking. Indeed, there is now a Centre for Democratic Network Governance at Roskilde University in Denmark. This unit supports normatively grounded network analysis with a focus on public governance (see, e.g., Sørensen and Torfing 2007). While we are far from a fully articulated and comprehensive normative theory of networks and governance, we can point more precisely to a number of normative issues that deserve serious consideration.

One key theme has been concern about the implications of networks for the accountability of public sector and other actors who sometimes coproduce policy-relevant action through causal mechanisms that are imperfectly understood and only partially monitored. This theme has been developed by some scholars (Heinrich, Lynn, and Milward 2010; Milward 1996; Milward, Provan, and Else 1997), especially as it pertains to patterns of contracting out by government. While some analysts see more dispersed and networked patterns as offering prospects for enhanced accountability (Behn 2001), most frame the normative issue as complex and contingent. ${ }^{6}$

Beyond the issue of accountability, a variety of additional normative challenges have been addressed, at least partially, in the literature. For instance, some of the key elements of democratic governance can be affected by the particulars of networked arrays; these include people's sense of responsibility — and its possible diffusion-responsiveness, and the potentially crucial features of deliberation, civility, and trust (for consideration of this set of normative concerns, see O'Toole 1997a).

Even beyond these considerations, those concerned with some of the normative consequences of networks and networking have explored several additional themes. These include concern about "dark networks," as discussed earlier; the potential for the use of social network analysis to assist in building community partnerships (Provan et al. 2005); consideration of the potential for networks to expand "systemic risk" or even crisis under some circumstances (Carboni and Milward 2012); the possibility that governmentmanaged networks can enhance the transparency and legitimacy of governance efforts (Klijn and Koppenjan 2000); and analysis of how networks and networking can work against equitable public service outcomes (O’Toole and Meier 2004a).

In short, although there are no sweeping injunctions about using or avoiding networks and networking in public administration, it is clear at this juncture that the subject taps a wide array of salient and value-laden considerations. The network theme has begun to be tied to a set of fundamental considerations important to society and its future direction.

\section{The Practical Agenda}

In "Treating Networks Seriously," I included some observations regarding the practical agenda for public administration and offered some very limited comments about the practical relevance of the networks theme. Some of these were, frankly, speculativeespecially given that there was at that time very little systematic evidence regarding the ubiquity of networks and networking behavior (i.e., the descriptive agenda). For instance, I suggested that "needed forms of management may be counterintuitive" (O'Toole 1997b, 47). For the most part, however, I indicated that this subject was largely terra incognita. Since then, some progress has been made in identifying the effective components of public management in such networked settings.

Of course, there is no simple set of detailed injunctions to flow from the work of the past two decades or so. But some useful contributions can be briefly referenced, and these results can be helpful heuristically for practicing public managers.

The most obvious point is that public managers ignore networks and networking at their own — and their programs'-peril. It is clear that the emergence of networks as prominent features of public administration by no means eliminates the role of hierarchy, and networks are not the only type of arrangement that can encourage collaborative management (Agranoff 2006). Still, virtually all public managers can expect either to work in networked arrangements at least some of the time or, at minimum, have to deal with others who are themselves enmeshed in such patterns. Public administrators, therefore, need to recognize and take into account such networks and networking as they go about their responsibilities.

Second, as indicated earlier, networks vary widely. Some are formally mandated, some are self-organized, and some are a combination of the two. The patterns may be simple and relatively modest in size, or they may involve scores of organizations and actors interacting in complex patterns. There may be intricate governance mechanisms for the network as a whole, or the pattern may be fluid and lacking in overt, overall governance. Because of such variation on several dimensions, managers should be wary of any general and precise injunctions for practice.

Third, and leaving aside disappointing possibilities like stalemate and inaction, it is important to remember that networks can produce unattractive or even destructive outcomes. Practicing managers 
should be aware of the potential for such results, particularly regarding issues on the normative network agenda as sketched earlier.

A fourth point is relevant: scholars have noted that even across mandated and "emergent" or self-organizing network settings, some general "challenges" for managers can be identified. Provan and Lemaire (2012), for instance, suggest that the main ones are these: varied levels of commitment to goals across the organizations involved, clashes between different organizational cultures, loss of autonomy (for those in individual organizations), possibly reduced accountability, and management complexity. They also note that in terms of process indicators of network effectiveness, ${ }^{7}$ broad characteristics are associated with effective networks: involvement at multiple levels, sensible network design, appropriate governance (different governance patterns are more or less appropriate for different situations), legitimacy, and stability (on this last point, see also O'Toole and Meier 2003).

Fifth, there has been some disagreement about the extent to which managing networks constitutes a fundamentally different set of tasks and skills than managing "solitary" public agencies. In their study of collaborative public management (an important category of network-and-networking instances, but still only one set of cases) at the local level in the United States, Agranoff and McGuire examine the details of a number of cases and then conclude that "the contacts, activities, policy tools, and other connections discovered in this study lead us to conclude that the capacities required to operate successfully in collaborative settings are different from the capacities needed to succeed at managing a single organization" $(2003,175)$. While they acknowledge that many questions about the effective practice of collaborative public management remain to be explored, they make an effort to begin an identification of - for instance-the particular skills needed for successful collaborative public management. These include those of determining how to select the best collaborative partners, along with understanding how best to begin, continue, and end collaborative processes, and knowing what decision rules to use when encountering some of the managerial challenges related to collaboration. They also emphasize the point that "in collaborative management, empowerment is based on information rather than authority" (179); and they consider some of the features of such settings that might aid in the information-based encouragement of collaboration, such as social capital-including "trust, norms, and operations of the network" — and shared learning (180). Indeed, the importance of learning and learning processes has been emphasized elsewhere (Agranoff 2006, 2012; see also Weber and Khademian 2008). But Agranoff (2012), too, has more recently emphasized that public management in all settings is significantly about collaboration, and he has also deemphasized somewhat the distinctiveness of networked settings while reminding others that "managers continue to do the bulk of their work within hierarchy" (Agranoff 2006, 57-58; see Fountain 2013, 17-18 for a treatment of the issue).

Indeed, an increasingly emphasized theme is that public managers in whatever institutional context need to be skilled in all the ways that collaboration can be encouraged and sustained. These include encouraging the right tone and direction very early in a collaborative process (Dawes, Cresswell, and Pardo
2009), discerning how to work through conflicts and power issues (Agranoff 2006), and understanding which kinds of organizational or network designs are suitable for which kinds of public problems (Provan and Lemaire 2012).

What we can say as a result of these studies and insights is that skills at collaboration, as well as at negotiation and the practical, goal-oriented use of social capital, are likely to be at a premium in network settings for public administrators. Further, we should attend to how to facilitate processes of social learning in such contexts, and it would be useful for researchers to focus more on this part of the agenda.

In more recent studies, some fairly specific injunctions for practice have sometimes been developed for particular forms of networked action. For instance, Fountain has offered a valuable set of researchgrounded observations and recommendations for public managers involved in interagency, explicitly collaborative initiatives in the U.S. federal government. For this important subset of networked patterns, her coverage can be quite useful (see also Verkuil and Fountain 2014).

As she points out, in such settings, managers need to operate strategically for collaboration through both people and processes. Such efforts necessarily entail the use of relationship skills, as well as organizational processes, because "many strategies, priorities, and goals of the government inherently lie across agencies" (Fountain $2013,8)$. These efforts constitute no easy task, particularly because important institutional obstacles constrain such collaborative efforts. ${ }^{8}$ She emphasizes that managing in collaborative settings involves high transaction costs, is typically demanding, and requires extra communication and persuasion.

Accordingly, "To build and sustain cross-agency collaborative management, managers need three sets of skills:

- First, understand and work strategically within the institutional environment.

- Second, develop and use interpersonal skills to build strong professional relationships and teams.

- Third, build capacity across boundaries through rigorous structures and processes with the extra commitment and coordination required to work across agency boundaries." This researchbased coverage is full of insights and guidance for effective practice in federal interagency collaborative efforts.

Beyond these points, additional injunctions regarding the practical agenda, as sketched in the original article, continue to be relevant. In particular, my initial analysis sought to encompass networks broadly construed, without an assumption that they are necessarily self-organized or explicitly designed for collaboration. Accordingly, public administrators would be well advised to conduct regular scanning of the networks in which (or with which) they work to inventory their principal contingencies and alliances, including indirect ties. Such administrators are unlikely to be able to encourage effective practice without knowledge of their interdependent contexts (O’Toole 1997b, 48). They should also bear 
in mind an important truth that was prominently emphasized by Barnard in his classic Functions of the Executive (1938): one should not assume that one possesses actual, working authority by virtue of having a formal position of responsibility. Barnard, it should be emphasized, was writing about authority within formal organizations, not across them; even within hierarchies, he argued, authority comes from below-it is contingent on the willingness of others to grant it. All the more so does this point hold in network settings. A key management challenge is likely to be to generate willing support and cooperation from others over whom any given manager has limited power.

How to do so is dependent on the particulars of a network setting, of course. Still, as I suggested in the initial article, administrators should look for chances to identify "common ground, practices, or procedures that serve most interests" represented in the network (O'Toole 1997b, 48). Public administrators can take action within the network as well as seek to modify the network array, if necessary, to encourage more favorable outcomes. For the former, one may be able to " $[\mathrm{u}]$ se information to heighten the salience of preferred choices; convey knowledge about how cooperation can serve interests of the others; honor confidences; and focus participants' perceptions on elements crucial for success. Network management involves trying to build trust among the participating parties." For the latter, administrators might "find ways to shift network membership toward more supportive coalitions; locate key allies at crucial nodes; try to alter agreements among the parties to heighten program salience; and buffer well-functioning arrays to limit uncertainty and complexity" (48).

In short, the literature of public administration now contains a considerable amount of useful reminders of how to encourage effective practice for managers involved in networks and/or engaged in networking action.

\section{Conclusion}

Research on networks and networking has made substantial progress, particularly on some questions - the descriptive agenda, for instance, and some aspects of the practical agenda. But considerable work remains to be done. In terms of the research agendas, we need to know much more about the ways in which networks and networking behavior can shape performance and affect the most salient values in our governance systems. Furthermore, how does management at the network level, not just the organizational level, influence performance? What accounts for the shifts in network dynamics over extended periods, and what difference do such changes make? Can we develop better explanations for the wide variation in the efficacy of transnational, especially multilateral, networks? Can we incorporate the systematic examination of large numbers of network cases with the detailed inclusion of structural and behavioral features of the individual networks - thus enhancing both extensiveness and intensiveness? Can the use of simulations through agent-based modeling provide better and more systematic understanding of how modifying certain network characteristics can have implications for network behavior and outcomes? Can we make progress at understanding what may be the differing dimensions of managerial networking with different clusters of actors and how these differences matter? Can we embed our examinations of networks and networking in public administration within multilevel models, thus developing more realistic depictions of the complex realities within which public managers frequently operate? And can we develop a more comprehensive understanding of the worrisome, not just the attractive, consequences of networked public action?

Given the considerable variation in types of network settings, particularly with regard to self-organized versus mandated networks, simple nostrums will have little value; we could greatly benefit from better theory that can successfully combine the elements of both. Such further developments would be of immense value to the practice of public administration. The world of public administration, in short, has for some time been treating networks seriously, but the work is far from complete.

\section{Acknowledgments}

I acknowledge with gratitude the assistance of Justin Stritch with research on some of the themes explored in this article, as well as for helpful comments on an earlier draft.

\section{Notes}

1. Citations from Publish or Perish software, February 2014; see Harzing (2007).

2. Some of these stage-setting points are also sketched in O'Toole (2010).

3. I consider in this article both networking behavior, particularly on the part of public managers, and the embedding of public action in networks themselves, regarded here as structural entities. There is an extensive literature on the subject of policy networks (see Isett et al. 2011; Lecy, Mergel, and Schmitz 2014) multiactor entities involved in the development and enactment of public policy—but the current article largely omits this work and concentrates on the administration of networks - structures of interdependence, in other words, involved in converting policy intention into action. Of course, boundaries between these two subjects are somewhat porous. "Networking" by managers involves boundary spanning, a subject of research for decades, but the former term emphasizes interactions in multiple directions and often for purposes beyond information exchange-including, sometimes, efforts to manage some larger networked array.

4. It is likely, furthermore, that the attention given to networks and networking by scholars will not slacken soon. The Journal of Public Administration Research and Theory has appointed in recent years a coeditor for networks, primarily because of the volume of studies submitted for consideration. Note, as well, the recent establishment of a new journal, Complexity, Governance, and Networks.

5. Inevitably, the useful research literature on collaboration is developed in many and varied directions, and this voluminous material cannot be reviewed here. See Agranoff $(2012,219-30)$, however, for brief coverage of many of these themes and strands of work. Also, on cross-sector collaboration, see Bryson, Crosby, and Stone (forthcoming).

6. The beginning of a theory of informal accountability in networks has also been offered (Romzek, LeRoux, and Blackmar 2012).

7. They correctly observe that research on outcomes for networks as a whole has been "scarce and Problematic" (Provan and Lemaire 2012, 643). See also Turrini et al. (2010), in which the authors review a considerable amount of the evidence on effectiveness.

8. Fountain $(2013,14-17)$ addresses in particular organizational and programmatic stovepipes, a federal legislative process that sends mixed messages, blurred lines of accountability, and a budget process that inhibits shared resources.

\section{References}

Agranoff, Robert. 2006. Inside Collaborative Networks: Ten Lessons for Public Managers. Public Administration Review 66(1): 56-65.

2012. Collaborating to Manage: A Primer for the Public Sector. Washington, DC: Georgetown University Press. 
Agranoff, Robert, and Michael McGuire. 2003. Collaborative Public Management: New Strategies for Local Governments. Washington, DC: Georgetown University Press.

Akkerman, Agnes, René Torenvlied, and Jelmer Schalk. 2011. Two-Level Effects of Inter-Organizational Network Collaboration on Graduate Satisfaction: A Comparison of Five Inter-College Networks in Dutch Higher Education. American Review of Public Administration 42(6): 654-77.

Andersen, Simon Calmer, and Peter B. Mortensen. 2010. Policy Stability and Organizational Performance: Is There a Relationship? Journal of Public Administration Research and Theory 20(1): 1-20.

Andrews, Rhys, George A. Boyne, Kenneth J. Meier, Laurence J. O’Toole, Jr., and Richard M. Walker. 2010. Wakeup Call: Strategic Management, Network Alarms, and Performance. Public Administration Review 70(5): 731-41. . 2011. Environmental and Organizational Determinants of External Networking. American Review of Public Administration 41(4): 355-74.

Barnard, Chester I. 1938. The Functions of the Executive. Cambridge, MA: Harvard University Press.

Behn, Robert D. 2001. Rethinking Democratic Accountability. Washington, DC: Brookings Institution Press.

Berry, Frances S., Ralph S. Brower, Sang Ok Choi, Wendy Xinfang Goa, HeeSoun Jang, Myungjung Kwon, and Jessica Ward. 2004. Three Traditions of Network Research: What the Public Management Research Agenda Can Learn from Other Research Communities. Public Administration Review 64(5): 539-52.

Breiger, Ronald, Eric Shoon, David Melamed, Victor H. Asal, and R. Karl Rethemeyer. 2014. Comparative Configurational Analysis as a Two-Mode Network Problem: A Study of Terrorist Group Engagement in the Drug Trade. Social Networks 36(1): 23-39.

Bryson, John M., Barbara C. Crosby, and Melissa M. Stone. Forthcoming. Design and Implementation of Cross-Sector Collaboration: What We Know Now That We Didn't Know Eight Years Ago. Public Administration Review.

Burt, Ronald. 1995. Structural Holes: The Social Structure of Competition. Cambridge, MA: Harvard University Press.

Carboni, Julia L., and H. Brinton Milward. 2012. Governance, Privatization, and Systemic Risk in the Disarticulated State. Special issue, Public Administration Review 72: S36-44.

Dawes, Sharon S., Anthony M. Cresswell, and Theresa A. Pardo. 2009. From "Need to Know" to "Need to Share": Tangled Problems, Information Boundaries, and the Building of Public Sector Knowledge Networks. Public Administration Review 69(3): 392-402.

Donahue, Amy K., Willow S. Jacobson, Mark D. Robbins, Ellen V. Rubin, and Sally C. Selden. 2004. Management and Performance Outcomes in State Government. In The Art of Governance: Analyzing Management and Administration, edited by Patricia W. Ingraham and Laurence E. Lynn, Jr., 125-51. Washington, DC: Georgetown University Press.

Elazar, Daniel J. 1962. The American Partnership: Intergovernmental Co-operation in the Nineteenth Century United States. Chicago: University of Chicago Press.

Elmore, Richard. 1985. Forward and Backward Mapping: Reversible Logic in the Analysis of Public Policy. In Policy Implementation in Federal and Unitary Systems: Questions of Analysis and Design., edited by Kenneth I. Hanf and Theo A. J. Toonen, 33-70. Dordrecht, Netherlands: Martinus Nijhoff.

Feiock, Richard C., and Scholz, John T., eds. 2010. Self-Organizing Federalism: Collaborative Mechanisms to Mitigate Institutional Collective Action Dilemmas. Cambridge, UK: Cambridge University Press.

Fountain, Jane. 2013. Implementing Cross-Agency Collaboration: A Guide for Federal Managers. Washington, DC: IBM Center for the Business of Government.

Frederickson, H. George. 1999. The Repositioning of American Public Administration. PS: Political Science and Politics 32(4): 701-12.

Graddy, Elizabeth A., and Ben Chen. 2006. Influences on the Size and Scope of Networks for Social Service Delivery. Journal of Public Administration Research And Theory 16(4): 533-52.
Hall, Thad E., and Laurence J. O’Toole, Jr. 2000. Structures for Policy Implementation: An Analysis of National Legislation, 1965-66 and 1993-94. Administration \& Society 31(6): 667-86.

- 2004. Shaping Formal Networks through the Regulatory Process. Administration \& Society 36(2): 1-22.

Harzing, A. W. 2007. Publish or Perish. http://www.harzing.com/pop.htm [accessed September 7, 2014].

Heinrich, Carolyn J., Laurence J. Lynn, Jr., and H. Brinton Milward. 2010. A State of Agents? Sharpening the Debate over the Extent and Impact of the Transformation of Governance. Supplement 1, Journal of Public Administration Research and Theory 20: 3-19.

Hennig, Marina, Ulrik Brandes, Jürgen Pfeffer, and Ines Mergel. 2012. Studying Social Networks: A Guide to Empirical Research. Frankfurt, Germany: Campus Verlag.

Hicklin, Alisa, Laurence J. O’Toole, Jr., and Kenneth J. Meier. 2008. Serpents in the Sand: Managerial Networking and Nonlinear Influences on Organizational Performance. Journal of Public Administration Research and Theory 18(2): 253-73.

Hjern, Benny, and Chris Hull. 1982. Implementation Research as Empirical Constitutionalism. European Journal of Political Research 10(2): 105-15.

Hjern, Benny, and David. O. Porter. 1981. Implementation Structures: A New Unit of Administrative Analysis. Organization Studies 2(3): 211-27.

Huxham, Chris, Siv Vangen, and Colin Eden. 2000. The Challenge of Collaborative Governance. Public Management Review 2(3): 337-52.

Isett, Kimberly R., Ines A. Mergel, Kelly LeRoux, Patricia A. Mischen, and Karl Rethemeyer. 2011. Networks in Public Administration Scholarship: Understanding Where We Are and Where We Need to Go. Supplement 1, Journal of Public Administration Research and Theory 21: i157-73.

Isett, Kimberly R., and Keith G. Provan. 2005. The Evolution of Dyadic Interorganizational Relationships in a Network of Publicly Funded Nonprofit Agencies. Journal of Public Administration Research and Theory 15(1): 149-65.

Jacobson, Willow S., Christine Kelleher Palus, and Cynthia J. Bowling. 2010. A Woman's Touch? Gendered Management and Performance in State Administration. Journal of Public Administration Research and Theory 20(2): 477-504.

Jokisaari, Markku, and Jukka Vuori. 2010. The Role of Reference Groups and Network Position in the Timing of Employment Service Adoption. Journal of Public Administration Research and Theory 20(1): 137-56.

Kickert, Walter J. M., Erik-Hans Klijn, and Joop F. M. Koppenjan, eds. 1997. Managing Complex Networks: Strategies for the Public Sector. Thousand Oaks, CA: Sage Publications.

Kiefer, John J., and Robert S. Montjoy. 2006. Incrementalism before the Storm: Network Performance for the Evacuation of New Orleans. Special issue, Public Administration Review 66: 122-30.

Kim, Soonhee, Shena Ashley, and W. Henry Lambright, eds. 2015. Public Administration in the Context of Global Governance. Cheltenham, UK: Edward Elgar.

Klijn, Erik-Hans, and Joop F. M. Koppenjan. 2000. Public Management and Policy Networks: Foundations of a Network Approach to Governance. Public Management: An International Journal of Research and Theory 2(2): 135-58.

Koliba, Christopher J., Russell M. Mills, and Asim Zia. 2011. Accountability in Governance Networks: An Assessment of Public, Private, and Nonprofit Emergency Management Practices Following Hurricane Katrina. Public Administration Review 71(2): 210-20.

Koppell, Jonathan G. S. 2010. World Rule: Accountability, Legitimacy, and the Design of Global Governance. Chicago: University of Chicago Press.

Koppenjan, Joop, and Erik-Hans Klijn. 2004. Managing Uncertainties in Networks: A Network Approach to Problem Solving and Decision Making. London: Routledge. 
Krueathep, Weerasak, Norma M. Riccucci, and Charas Suwanmala. 2010. Why Do Agencies Work Together? The Determinants of Network Formation at the Subnational Level of Government in Thailand. Journal of Public Administration Research and Theory 20(1): 157-85.

Lafferty, William, ed. 2004. Governance for Sustainable Development: The Challenge of Adapting Form to Function. Cheltenham, UK: Edward Elgar.

Lecy, Jesse, Ines A. Mergel, and Hans Peter Schmitz. 2014. Networks in Public Administration: Current Scholarship in Review. Public Management Review 16(5): 643-65.

Lundin, Martin. 2007. Explaining Cooperation: How Resource Interdependence, Goal Congruence, and Trust Affect Joint Actions in Policy Implementation. Journal of Public Administration Research and Theory 17(4): 651-72.

Matland, Richard E. 1995. Synthesizing the Implementation Literature: The Ambiguity-Conflict Model of Policy Implementation. Journal of Public Administration Research and Theory 5(2): 145-74.

Meier, Kenneth J., Simon Calmer Andersen, Laurence J. O’Toole, Jr., Nathan Favero, and Søren C. Winter. Forthcoming. Taking Managerial Context Seriously: Public Management and Performance in U.S. and Denmark Schools. International Public Management Journal.

Meier, Kenneth J., and Laurence J. O’Toole, Jr. 2001. Managerial Strategies and Behavior in Networks: A Model with Evidence from U.S. Public Education. Journal of Public Administration Research and Theory 11(3): 271-93.

- 2003. Public Management and Educational Performance: The Impact of Managerial Networking. Public Administration Review 63(6): 689-99.

- 2005. Managerial Networking: Issues of Measurement and Research Design. Administration \& Society 37(5): 523-41.

- 2009. The Proverbs of New Public Management: Lessons from an EvidenceBased Research Agenda. American Review of Public Administration 39(1): 4-22.

Milward, H. Brinton. 1996. Symposium on the Hollow State: Capacity, Control, and Performance in Interorganizational Settings. Journal of Public Administration Research and Theory 6(2): 193-96.

Milward, H. Brinton, Patrick Kenis, and Jörg Raab, eds. 2006. Symposium: The Control of Legal and Illegal Networks. International Public Management Journal 9(3).

Milward, H. Brinton, Keith G. Provan, and Barbara Else. 1997. What Does the Hollow State Look Like? In Public Management: The State of the Art, edited by Barry Bozeman, 309-22. San Francisco: Jossey-Bass.

Milward, H. Brinton, Keith G. Provan, Amy Fish, Kimberly R. Isett, and Kun Huang. 2010. Governance and Collaboration: An Evolutionary Study of Two Mental Health Networks. Supplement 1, Journal of Public Administration Research and Theory 20: i125-41.

Moynihan, Donald P. 2009. The Network Governance of Crisis Response: Case Studies of Incident Command Systems. Journal of Public Administration Research and Theory 19(4): 895-915.

- 2012. Extra-Network Organizational Reputation and Blame Avoidance in Networks: The Hurricane Katrina Example. Governance 25(4): 567-88.

Nicholson-Crotty, Sean, and Laurence J. O’Toole, Jr. 2004. Public Management and Organizational Performance: The Case of Law Enforcement Agencies. Journal of Public Administration Research and Theory 14(1): 1-18.

Nicolaidis, Kalypso, and Robert Howse, eds. 2001. The Federal Vision: Legitimacy and Levels of Governance in the United States and the European Union. Oxford, UK: Oxford University Press.

O'Leary, Rosemary, and Lisa Blomgren Bingham, eds. 2009. The Collaborative Public Manager: New Ideas for the Twenty-First Century. Washington, DC: Georgetown University Press.

Ostrom, Elinor. 1990. Governing the Commons: The Evolution of Institutions for Collective Action. Cambridge, UK: Cambridge University Press.

- 2005. Understanding Institutional Diversity. Princeton, NJ: Princeton University Press.
O’Toole, Laurence J., Jr. 1997a. The Implications for Democracy in a Networked Bureaucratic World. Journal of Public Administration Research and Theory 7(3): 443-59.

- 1997b. Treating Networks Seriously: Practical and Research-Based Agendas in Public Administration. Public Administration Review 57(1): 45-52.

- 2010. The Ties That Bind? Networks, Public Administration, and Political Science. PS: Political Science and Politics 43(1): 7-14.

O’Toole, Laurence J., Jr., and Kenneth I. Hanf. 2002. American Public Administration and Impacts of International Governance. Special issue, Public Administration Review 62: 158-69.

O’Toole, Laurence J., Jr., Kenneth I. Hanf, and Peter Hupe. 1997. Managing Policy Implementation in Complex Networks. In Managing Complex Networks: Network Management and the Public Sector, edited by Walter J. M. Kickert, ErikHans Klijn, and Joop F. M. Koppenjan, 135-51. London: Sage Publications.

O’Toole, Laurence J., Jr., and Kenneth J. Meier. 2003. Plus ça Change: Public Management, Personnel Stability, and Organizational Performance. Journal of Public Administration Research and Theory 13(1): 43-64.

—. 2004a. Desperately Seeking Selznick: Co-optation and the Dark Side of Public Management in Networks. Public Administration Review 64(6): 681-93.

— 2004b. Public Management in Intergovernmental Networks: Matching Structural and Behavioral Networks. Journal of Public Administration Research and Theory 14(4): 469-94.

- 2009. The Human Side of Public Organizations: Contributions to Organizational Performance. American Review of Public Administration 39(5): 499-518.

. 2011. Public Management: Organizations, Governance, and Performance. Cambridge, UK: Cambridge University Press.

. 2014. Public Management, Context, and Performance: In Quest of a More General Theory. Journal of Public Administration Research and Theory. Published electronically on March 28. doi:10.1093/jopart/muu011.

O'Toole, Laurence J., Jr., and Robert S. Montjoy. 1984. Interorganizational Policy Implementation: A Theoretical Perspective. Public Administration Review 44(6): 491-503.

O’Toole, Laurence J., Jr., and Mogens Jin Pedersen. 2011. Skoleledelsens Eksterne Samarbejde [External Cooperation of School Leadership]. In Ledelse, Laring og Trivsel i Folkeskolerne [Leadership, Learning, and Well-Being in Schools], edited by Simon Calmer Andersen and Søren C. Winter, 77-86. Copenhagen, Denmark: Danish National Centre for Social Research.

Poteete, Amy R., Marco A. Janssen, and Elinor Ostrom. 2010. Working Together: Collective Action, The Commons, and Multiple Methods in Practice. Princeton, NJ: Princeton University Press.

Pressman, Jeffrey L., and Aaron Wildavsky. 1984. Implementation: How Great Expectations in Washington Are Dashed in Oakland. 3rd ed. Berkeley: University of California Press.

Provan, Keith G., and Kun Huang. 2012. Resource Tangibility and the Evolution of a Publicly Funded Health and Human Services Network. Public Administration Review 72(3): 366-75.

Provan, Keith G., and Robin H. Lemaire. 2012. Core Concepts and Key Ideas for Understanding Public Sector Organizational Networks: Using Research to Inform Scholarship and Practice. Public Administration Review 72(5): 638-48.

Provan, Keith G., and H. Brinton Milward. 1995. A Preliminary Theory of Interorganizational Network Effectiveness: A Comparative Study of Four Community Mental Health Systems. Administrative Science Quarterly 40(1): $1-33$.

— 2001. Do Networks Really Work? A Framework for Evaluating PublicSector Organizational Networks. Public Administration Review 61(4): 414-23.

Provan, Keith G., Mark A. Veazie, Lisa K. Staten, and Nicolette I. Teufel-Shone. 2005. The Use of Network Analysis to Strengthen Community Partnerships. Public Administration Review 65(5): 603-13. 
Raab, Jörg, and Patrick Kenis. 2009. Heading toward a Society of Networks: Empirical Developments and Theoretical Challenges. Journal of Management Inquiry 18(3): 198-210.

Raab, Jörg, and H. Brinton Milward. 2003. Dark Networks as Problems. Journal of Public Administration Research and Theory 13(4): 413-39.

Rho, Eunju. 2013. Network Dynamics in Local Governments: Exogenous and Endogenous Determinants of Changes in Managerial Networking. PhD diss., University of Georgia.

Robinson, Scott E. 2006. A Decade of Treating Networks Seriously. Policy Studies Journal 34(4): 589-98.

Roch, Christine H., David Pitts, and Ignacio Navarro. 2010. Representative Bureaucracy and Policy Tools: Ethnicity, Student Discipline and Representation in Public Schools. Administration \& Society 42(1): 38-65.

Romzek, Barbara S., Kelly LeRoux, and Jeannette M. Blackmar. 2012. A Preliminary Theory of Informal Accountability among Network Organizational Actors. Public Administration Review 72(3): 442-53.

Scharpf, Fritz W. 1993. Coordination in Hierarchies and Networks. In Games in Hierarchies and Networks: Analytical and Empirical Approaches to the Study of Governance Institutions, edited by Fritz W. Scharpf, 7-23. Frankfurt, Germany: Campus Verlag.

Selznick, Philip. 1949. TVA and the Grass Roots: A Study in the Sociology of Formal Organization. Berkeley: University of California Press.
Sørensen, Eva, and Jacob Torfing, eds. 2007. Theories of Democratic Network Governance. Basingstoke, UK: Palgrave Macmillan.

Torenvlied, René. 2012. De Mantra van coördinatie of het optimisme over netwerken in de publieke sector [The Mantra of Coordination, or the Optimism about Networks in the Public Sector]. Leiden, Netherlands: Leiden University.

Torenvlied, René, Agnes Akkerman, Kenneth J. Meier, and Laurence J. O’Toole, Jr. 2013. Organizational Instability and Performance: The Moderating Effect of School Management in Dutch Primary Education. Unpublished manuscript.

Turrini, Alex, Daniela Cristofoli, Francesca Frosini, and Greta Nasi. 2010. Networking Literature about Determinants of Network Effectiveness. Public Administration 88(2): 528-50.

Verkuil, Paul R., and Jane E. Fountain. 2014. The Administrative Conference of the United States: Recommendations to Advance Cross-Agency Collaboration under the GPRA Modernization Act. Public Administration Review 74(1): $10-11$.

Walker, Richard M., Laurence J. O’Toole, Jr., and Kenneth J. Meier. 2007. It's Where You Are That Matters: The Networking Behaviour of English Local Government Officers. Public Administration 85(3): 739-56.

Weber, Edward P., and Anne M. Khademian. 2008. Wicked Problems, Knowledge Challenges, and Collaborative Capacity Builders in Network Settings. Public Administration Review 68(2): 334-49.

\section{If you are interested in submitting a manuscript to}

\section{Public Administration Review,}

please review the guidelines under publications at www.aspanet.org and follow the submission instructions. 